\title{
Passenger Requirements of a Public Transport Ticketing System
}

\author{
Brian Caulfield \\ Centre for Transport Research \\ Department of Civil, Structural and Environmental Engineering \\ Trinity College Dublin \\ Dublin 2 \\ Ireland \\ Tel: +353 (0) 16082537 \\ Fax: +353(0) 16773072 \\ Email: caulfieb@tcd.ie \\ Margaret O’Mahony (CORRESPONDING AUTHOR) \\ Centre for Transport Research \\ Department of Civil, Structural and Environmental Engineering \\ Trinity College Dublin \\ Dublin 2 \\ Ireland \\ Tel: $+353(0) 16082084$ \\ Fax: +353(0) 16773072 \\ Email: margaret.omahony@tcd.ie
}




\begin{abstract}
Currently in Dublin the system of public transport ticketing is under review and there are plans to introduce a multi-modal, multi-operator ticketing system. It is planned that this system will be operated via smart card technology, whereby passengers can pass between mode and operator with ease of use.

The purpose of this paper is to examine what passengers require from their ticketing system with regard to the means and method of payment and the kind of information they require from an at-stop ticketing vending machine. Between January and February 2004 a detailed survey of a representative sample of 1,005 adults aged 15 and over in Dublin was completed using face-to-face at home interviews. With the format of the ticketing system decided upon (contact-less smart cards) the research focused upon the payment options and the design of the at-stop/station ticket vending machines.

The first section of the paper looks at international examples of ticketing systems and how Intelligent Transport Systems (ITS) applications have been used to aid passengers' comprehension of the ticketing system and ease of use of the system. The second section describes the methodology used in the data collection. The third section details the passenger requirements from a ticketing system based upon the data collected from the Dublin survey. The final section of the paper details the conclusions that can be drawn from the data gathered in the Dublin study.
\end{abstract}




\section{INTRODUCTION}

Dublin, the capital city of Ireland, currently has a population of 1.2 million, and is served by the most extensive public transport system in the country. This system contains three main modes of public transport, bus, light rail transit (LRT) and heavy rail. The bus network is still the backbone of this system with 12 radial quality bus corridors (QBC's) to date. The main operator Dublin Bus operates a fleet of 1,100 buses and in 2003 operated 149 million passenger journeys (1). The introduction of QBC's in Dublin in 1996 has been a great success, with a significant modal shift realised and buses providing competitive commute times versus private cars (2). Since the 1980's Irish Rail have operated a heavy rail service called Dublin Area Rapid Transit (DART). The DART is currently undergoing an upgrade due to be completed in 2005 and this will increase the capacity of the service from 11,800 to 16,000 passengers per hour per direction (3). At present the service provided 22 million passenger journeys in 2003 (1). The most recent addition to the public transport network is the LRT system called Luas with the first two lines of the network opened in June and August 2004. The current capacity of Luas is 6,400 passengers per direction per hour (4).

Public transport in Dublin is a mixture between bus and rail and as identified in many other cities one of the best methods for aiding integration between modes is by introducing a system of integrated ticketing. This paper describes the system to be introduced in Dublin and the research undertaken on possible changes in ticketing mediums and the vending machines.

The first section of the paper examines the old and new ticketing systems in Dublin. The following section discusses some similar systems that have been introduced internationally. The final section looks at the study conducted on the different options of ticket payment, payment methods and the options for information from ticket vending machines.

\section{PUBLIC TRANSPORT TICKETING IN DUBLIN}

\section{The Current Ticketing System}

The current ticketing system in Dublin is a mixture between paper based and magnetic strip ticketing. The magnetic strip system is a system whereby passengers validate their tickets as they enter the bus or pass through a gate to gain access to a train. These tickets have a pre-stored number of trips and passengers can use them on both Dublin Bus and Irish Rail services. To date on Dublin bus services a third of all passengers use these cards for their bus journeys. All bus and rail service also provide conventional paper tickets.

One of the major shortcomings of the current system is that it is not fully integrated between operators and modes. Another fault in the system is that passengers wishing to travel a multi-modal or operator trip have to buy a ticket each time they enter a new vehicle, except in the case of Luas and bus combined fares where one ticket will suffice. It is proposed that under the new system that the financial penalty to integration will be removed for transfers between all modes. 


\section{The Integrated Ticketing System}

One of the main objectives of the new ticketing system is to remove ticketing as a barrier to the integration of public transport in Dublin. In 2001 the Minister for Transport commissioned the Railway Procurement Agency (RPA) to design and implement a system of integrated ticketing (5). Subsequently a decision was made to introduce contact-less smart card ticketing. This decision was based upon the need to have a system that would cope with multiple operators and modes, to reduce boarding times due to speed of ticket validation and their capacity to store information.

It is proposed that all public transport operators will comply with this system of ticketing and offer their passengers the option of smart card tickets. The design and specification of the system has now been finalised and the first tests of the system will commence in October 2004. It is planned after a trial period with one of the private bus operators to introduce the system to Luas and have system-wide coverage of all operators and modes by December 2005 (6). It has been agreed that this initial trial period will be operated on Morton's coaches, a private bus company operating services in Dublin. This trial period will for the first time in Dublin utilise pre-paid contact-less smart cards, and operate a check in and check out (CICO) on their bus services. The purpose of this CICO system is two-fold [1] to ensure accurate fares under a distance based scheme [2] the operator will have better information on their passengers movements aiding transport planning (6).

\section{Ticket Vending Machines}

The majority of ticketing machines in Ireland are provided for rail services. Irish rail provides ticketing machines at all 29 DART stations, as seen in Figure 1. This system provides information on the cost of the journey, and enables payment by cash (notes and coins), credit and debit cards. These vending machines are also available at mainline rail stations providing tickets for all rail services in the country.

The system provided on the Luas, as seen in Figure 2, provides information on the route and fare, and has the same payment options provided by the Irish Rail system. The Luas has ticketing machines located at 36 stops along the two Luas lines (4). These systems are very similar to the systems provided in Portland, Oregon, in that they provide the same levels of information and they are located at over 60 stops/stations across the city (7).

\section{INTELLIGENT TRANSPORT SYSTEMS (ITS) APPLICATIONS FOR TICKETING SYSTEMS}

Internationally, smart card and integrated ticketing is seen as an increasingly attractive option for both passengers and public transport operators alike. The benefits they provide for all users are well documented.

Chicago introduced a system of smart card ticketing in 1997. By 1999, the use of cash as the method of payment on bus dropped by $24 \%$ and $6 \%$ on rail (8). Initial customer satisfaction ratings of the smart card system demonstrated that $93 \%$ of users were 'very satisfied' with the system. Further research completed on the Chicago system with regard to recharging their cards, found that $17 \%$ of respondents would be willing to recharge cards by payment on the internet, and 8\% would use ATM's (8). 
The Washington Metropolitan Area Transit Authority (WMATA) has also introduced a system of smart card ticketing called SmarTrip. Since the introduction of the system in 1999 approximately 1,686 buses have been equipped with smart card fare boxes (9). Key to the success of this system is that all operators in the Washington DC and Baltimore MD region have signed up to introduce a fare structure that will allow passengers to travel seamlessly between modes and operators.

Transport for London introduced a system of integrated ticketing using smart cards called Oystercard in 2002. The system has been greatly expanded and since May 2004 it has been available on a pre-paid basis on all public transport services in London. Oystercard is the first large scale integrated ticketing system to be introduced in the UK, and already Londoners are experiencing reduced queuing times in underground stations, and time spent at bus stops. Transport for London has estimated that with the pre-paid system in place they will save £30million (Sterling) per year, in operating costs (10). Given the initial success of the system there are plans to extend the system to national rail services across the UK.

Hong Kong's Octopus ticketing system is one of the largest smart card ticketing systems in the world. Since the launch of the system, 6.3 million cards are in circulation, and it is estimated that at least $80 \%$ of the population in Hong Kong has at least one card (11). Hong Kong like Dublin has a vast number of transport operators and modes providing services around the city. Therefore in order for the Octopus system to work, it was essential to have operators in agreement. Operators in Hong Kong were convinced to join in the Octopus programme having seen the benefits such a system can offer such as; fraud prevention, enhanced customer service and reduction in cash handling costs (11).

Preliminary market research has been conducted by the Railway Procurement Agency (RPA) on the system to be introduced in Dublin and has demonstrated positive results. A survey of 1,005 individuals in Dublin demonstrated that 572(57\%) thought that the system was a 'very good idea', and 292(29\%) that it was a 'fairly good idea'. In the same survey, respondents were asked if using the integrated smart card system would make travelling on public transport better, 703(70\%) of respondents agreed that it would result in a better public transport service (6).

\section{METHODOLOGY}

The data was collected between January and February 2004 by the RPA. This consisted of a detailed survey of a representative sample of 1,005 adults aged 15 and over in Dublin, during face-to-face interviews at home. Using the same survey the authors incorporated questions on the specifications of the ticketing system and it is this research that is documented below.

The socio-economic and demographic details are listed in Table 1. The socioeconomic characteristics of the respondents indicate an even distribution of gender and age. The distribution of the respondents by region is consistent with the appropriate populations of the regions as seen in Table 1.

The results for modal split in Table 2 indicate that the majority of respondents use bus, divided between Dublin Bus (53\%) and any other bus (18\%), with the rail options divided between DART/Heavy rail $(17 \%)$ and any other train $(12 \%)$. It should be noted 
that this survey was completed before the Luas lines were opened and therefore the modal split outlined in Table 2 does not incorporate this mode.

\section{PASSENGER REQUIREMENTS FROM THE PROPOSED TICKETING SYSTEM}

In order to ascertain what passengers require from a public transport ticketing system, data was collected on passenger preferences on the method and means of ticket purchase, and the information provided by a ticket vending machine. Passengers were asked to rank three options presented to them. The following section details the survey.

\section{Method of Ticket Payment}

This section deals with the method passengers would like to use to make payment for their public transport trips. Passengers were offered the following alternatives: [1] Onboard purchase (no change given), [2] Purchase ticket from mobile phones via Short Message Service (SMS) and [3] Purchase ticket from a vending machine. Currently in Dublin option one is available to all bus users and option three is available to all train users with a limited number of vending machines available for bus users.

The second option of purchase via SMS is a new alternative offered to passengers in this survey to ascertain how they would react to the possibility of pre-purchasing their ticket using SMS. Passengers were offered the following alternatives to rank from $1-3$ with 1 indicating their highest preference.

The results indicated that passengers gave the highest preference to purchasing their tickets at a vending machine as opposed to any other method with $391(39 \%)$ respondents raking it as their first preference and $426(42 \%)$ as their second preference as seen in Figure 3. 42\% of females compared with 35\% of males give this their first preference. $42 \%$ and $46 \%$ of the age groups 35-44 and 45-64 respectively gave this their first preference compared with the other age groups in the range 33-36\%. 45\%(215) of the $\mathrm{AB} / \mathrm{C} 1$ social class groups (A - upper middle class, $\mathrm{B}$ - middle class, $\mathrm{C} 1$ - lower middle class) selected this as first preference compared with $32 \%(162)$ of the C2/DE (C2 - skilled working class, D - working class and E - at lowest level of subsistence) group and $52 \%(14)$ of the F (farmers) group. $40 \%(212)$ of each of the working and (40 individuals) retired groups gave this their first preference compared with 29\% (38) of the student group. Paying for the ticket on-board with cash (no change given) was ranked second with 327 (33\%) demonstrating this would be their first preference and $325(32 \%)$ their second preference. There was little difference between males and females in terms of first preferences $(32 \% / 33 \%)$. Only $22 \%(53)$ of the $15-24$ age group gave this a first preference compared with $35 \%(70), 28 \%(51)$ and $35 \%(94)$ for each of the other age groups respectively (age increasing). 25\%(119) of the $\mathrm{AB} / \mathrm{C} 1$ social class groups gave a first preference compared with 39\%(199) of the C2/DE group and 33\%(9) of the F group. $47 \%(47)$ of the retired group chose first preference to this question compared with $30 \%(160)$ of the working group and $20 \%(26)$ of the student group. Purchasing tickets via SMS was ranked third with 265 (26\%) first preference responses and $211(22 \%)$ second preference responses. As one might expect, the age group with the largest number of first preferences for this option was the youngest with 44\%(105) selecting this option compared with $28 \%(57$ and 50 ) for the next older two groups and only $17 \%(45)$ of the 
45-64 age group. Social class group had little impact in relation to first preferences in this case. A considerably larger number of those individuals in Dublin $(32 \% / 218)$ selected this as a first preference compared with between 4-21\% (3-18) for the other counties, although the low numbers of individuals from the other counties may be a factor here. $51 \%(66)$ of the student group gave this a first preference compared with $29 \%(155)$ of the working group and 5\%(5) of the retired group. This option was included as it is a method of payment being introduced in some cities. Perhaps surprisingly, even given the high proportion of Irish adults that use mobile phones $(88 \%)$ this option was rated third overall in terms of first preferences (11).

\section{Medium of Ticket Payment}

The medium of ticket payment at vending machines is examined in this section. The following options were presented to respondents; [1] Tickets paid for with cash (no change given, no notes), [2] Tickets paid for with cash (no change given, no notes) and credit and debit cards and [3] Tickets paid for with cash (change given) and credit and debit cards. Passengers were asked to rank alternatives from 1-3 with 1 indicating their highest preference. The purpose of this question was to ascertain how many payment options passengers require at vending machines.

The results outlined in Figure 4 indicated that passengers would like a wide range of payment options to chose from with the option of 'Tickets paid for with cash (change given) and credit and debit cards' as preferred means of payment with $583(58 \%)$ respondents indicating this to be their first preference and $200(20 \%)$ their second. $60 \%(287)$ of males and 56\%(296) selected this as first preference. $62 \%(111)$ of the $35-$ 44 age group compared with $56 \%-59 \%$ of the other groups. $60 \%(286)$ of the $\mathrm{AB} / \mathrm{C} 1$ and $56 \%(281)$ of the $\mathrm{C} 2 / \mathrm{DE}$ group selected this as first preference as did 52\%(51) of retired, $60 \%(323)$ of working and 58\%(75) of students. The second option of 'Tickets paid for with cash (no change given, no notes) and credit and debit cards' was ranked second with $106(11 \%)$ of first preferences and with $512(53 \%)$ of second preferences resulting in it being ranked second. However, if one considers only first preferences alone this option received the lowest number. $13 \%(60)$ of males and $9 \%(46)$ of females give this a first preference. Between $10 \%-12 \%$ of all age groups did the same except only $6 \%(7)$ of the $65+$ preferred it. Social class made little difference to first preferences but a lower number $(7 \% / 7)$ of retired compared with $12 \%$ of working and student groups gave it a first preference. The third ranked option when considering first and second preferences combined was to have 'Tickets paid for with cash (no change given, no notes)' with $291(29 \%)$ of first preferences and $253(25 \%)$ of second preferences. $24 \%(117)$ of males compared with $33 \%(174)$ of females gave this option their first preference. Larger percentages, $32 \%$ and $35 \%$, of the youngest and oldest age group respectively compared with $24 \%-28 \%$ of the other age groups gave this their first preference. $26 \%$ (122) of the $\mathrm{AB} / \mathrm{C} 1$ and $32 \%(162)$ of the $\mathrm{C} 2 / \mathrm{DE}$ group selected first preference as did $26 \%(139)$, $34 \%(34)$ and $29 \%(38)$ of the working, retired and student groups, respectively.

The results from this question demonstrate that passengers have a higher preference for more payment options, and that the option of change provided by the machine was very important as this is the only difference between options three and two. This is demonstrated by the fact that the difference between the first preference responses of the two options is 477 (47\%). 


\section{Passenger Information}

This final question in the survey pertains to at-stop/station ticket vending machines. This question asked what types of information passengers require from a vending machine. Respondents were offered the following options [1] Information on the cost of the journey, [2] Information given on the cost, and the route of that mode and [3] Information on the cost, the route and an estimated time of arrival of that service. Passengers were asked to rank alternatives from 1-3 with 1 indicating their highest preference.

The results are detailed in Figure 5. The results indicate that the option of having 'information on the cost, the estimated time of arrival of the service' as their highest preference with $602(61 \%)$ of first and $184(18 \%)$ of second preference responses. About $60 \%$ of both males and females gave this option their first preference as did each of the age groups. $63 \%(300)$ of the $\mathrm{AB} / \mathrm{C} 1$ social group compared with $57 \%(286)$ of the $\mathrm{C} 2 / \mathrm{DE}$ group gave it a first preference. There was little difference in response between working, retired and students. This option requires that vending machines be equipped with a visual display unit measuring the estimated time of arrival of each service, and therefore require significant investment. Having information on 'the cost, and the route of that mode' was ranked second with 154(16\%) of first preferences and the majority of second preferences with $646(65 \%)$ although on the basis of first preferences alone, it would be ranked third. Looking at the first preferences in more detail, similar percentages $(16 \%)$ of both males and females selected this option. The age group percentages ranged from $14 \%$ to $17 \%$ with the youngest and oldest group giving the lowest number of first preferences to this option. There was little difference in terms of social group or whether individuals were working, retired or students. The option of 'information given on the cost of the journey' was ranked third on the basis of combined first and second preferences. This option received $231(23 \%)$ of first preferences and 148(15\%) of second preferences. On the basis of first preferences it would be ranked second. In relation to first preferences, there was no difference between males and females but a larger percentage $(27 \% / 63)$ of the youngest age group gave this a first preference compared with $21-23 \%$ of the other age groups. 20\%(95) of the $\mathrm{AB} / \mathrm{C} 1$ social class group compared with $25 \%(128)$ of the $\mathrm{C} 2 / \mathrm{DE}$ gave it a first preference. In relation to the regions, a larger proportion of those in the regions outside Dublin (24\%-44\%) selected this as first preference compared with 18\%(125) of those in Dublin. This may be related to those individuals having longer journeys with cost rather than route having more significance. It would seem from these results that the cost and estimated time of arrival are important in terms of information provision.

\section{CONCLUSIONS}

The results of this study are as follows:

1. When ticketing systems similar to the one planned for Dublin were introduced internationally they have demonstrated that passengers have responded positively to the system.

2. As seen in the international example the key to providing a successful system is to ensure agreement between operators. 
3. The results from the initial market research undertaken in Dublin indicate a positive response to the proposed system.

4. Respondents indicated when questioned about what type of information they require to be provided at vending machines that more information was better. Responses demonstrated a high preference for the option of having information on the cost, route and an estimated time of arrival of their service.

5. Similar to the previous finding, when asked about the number of payment options required, respondents indicated a high preference for the widest possible number of options.

6. Payment methods were also examined in this study, the results of which demonstrated that passengers had a high preference for purchase at vending machines.

7. Interestingly, purchasing tickets via mobile phones received the lowest number of first preferences overall but, as expected, larger numbers of younger people and students preferred this method. Conversely, smaller numbers of these two groups gave payment on board (no change given) a first preference. However, given the proportion of Irish adults who regularly use mobile phones $(88 \%)$, the overall ranking of this method as the least preferred was unexpected.

\section{ACKNOWLEDGMENT}

The research is supported by the Department of Transport under the Pilot Transport Research Programme, administered by the Higher Education Authority. The authors would also like to thank the Railway Procurement Agency for their assistance in gathering the data.

\section{REFERENCES}

1. Córas Iompair Éireann, (2004), Annual Accounts 2003, Dublin, Ireland

2. Caulfield, B. and O'Mahony, M.M, Transit Capacity and Quality of Service Manual Applied to a Bus Corridor in Dublin, Ireland, Transportation Research Record, 1887, 2004, p195 - 204

3. Irish Rail, http://www.irishrail.ie/projects/dart_and_suburban_enhancement.asp, Accessed, $16^{\text {th }}$ June 2004

4. O'Mahony, M., (2004), Light Rail Transit in Dublin, (CD-ROM) $83^{\text {rd }}$ Annual Meeting of the Transportation Research Board. Washington DC, January 2004

5. Department of Transport (2001), Proposal for Integrated Ticketing in the Greater Dublin Area, Report of the Integrated Ticketing Committee, Dublin, Ireland, 2001

6. Railway Procurement Agency, (2004), http://www.rpa.ie/?id=32, Accessed, ${ }^{\text {th }}$ July 2004

7. Tri-Met, (2004), http://www.trimet.org/fares/tvm.htm, Accessed, $5^{\text {th }}$ July 2004

8. Foote, J. P. and Stuart, G.D, (2002), 'Testing Customer Acceptance of Smart Cards at the Chicago Transit Authority' (CD-ROM) $81^{\text {st }}$ Annual Meeting of the Transportation Research Board. Washington DC, January 2002 
9. Maxey. C. and Benjamin. P. (2001),' Seamless Fare Collection: Using Smart Cards for Multiple-Mode Transit Trips', Proceedings of the APTA Rail Transit Conference, 2001

10. Transport for London, The Transport for London Business Plan, to sustain London's growth and prosperity for the $21^{\text {st }}$ Century, 2004, London, UK

11. Eddie. S., (2003), 'Smart Card Ticketing for Better Statistics on passenger 'Volume \& Use of these Statistics'. http://www.omnipurse.com/smartcarddata.pdf, Accessed June 17, 2003.

12. Commission for Communications Regulation, (2004), Irish Communications Market, Quarterly Key Data, June 2004, Dublin, Ireland

\section{TABLES AND FIGURES}

\section{TABLES}

Table 1: Demographics of the sample

Table 2: Transport Mode Currently Used

\section{FIGURES}

Figure 1: Irish Rail Ticketing Machine

Figure 2: Luas Ticketing Machine

Figure 3: Ticket Purchase

Figure 4: Ticket Payment Methods

Figure 5: Information Provided 
TABLE 1: DEMOGRAPHICS OF THE SAMPLE

\begin{tabular}{|c|c|c|}
\hline & No. of Observations & Percentage \\
\hline \multicolumn{3}{|l|}{ Gender: } \\
\hline Male & 479 & 48 \\
\hline Female & 526 & 52 \\
\hline \multicolumn{3}{|l|}{ Age: } \\
\hline $15-24$ & 237 & 24 \\
\hline $25-34$ & 202 & 20 \\
\hline $35-44$ & 180 & 18 \\
\hline $45-64$ & 270 & 26 \\
\hline $65+$ & 116 & 12 \\
\hline \multicolumn{3}{|c|}{ Social Class } \\
\hline $\mathrm{AB}$ & 101 & 10 \\
\hline $\mathrm{C} 1$ & 372 & 37 \\
\hline $\mathrm{C} 2$ & 248 & 25 \\
\hline $\mathrm{DE}$ & 256 & 25 \\
\hline $\mathrm{F}$ & 27 & 3 \\
\hline \multicolumn{3}{|l|}{ Region } \\
\hline Dublin & 685 & 68 \\
\hline Kildare & 97 & 10 \\
\hline Louth & 63 & 6 \\
\hline Meath & 80 & 8 \\
\hline Wicklow & 79 & 8 \\
\hline \multicolumn{3}{|c|}{ Employment Status } \\
\hline Working & 534 & 53 \\
\hline Retired & 99 & 10 \\
\hline Student & 130 & 13 \\
\hline Other & 240 & 24 \\
\hline
\end{tabular}


TABLE 2: TRANSPORT MODE CURRENTLY USED

\begin{tabular}{lll}
\hline Mode & No. of Observations & Percentage \\
\hline Dublin Bus & 564 & $53 \%$ \\
\hline Other Bus & 184 & $18 \%$ \\
\hline DART (Heavy Urban Rail) & 185 & $17 \%$ \\
\hline All Trains & 121 & $12 \%$ \\
\hline
\end{tabular}




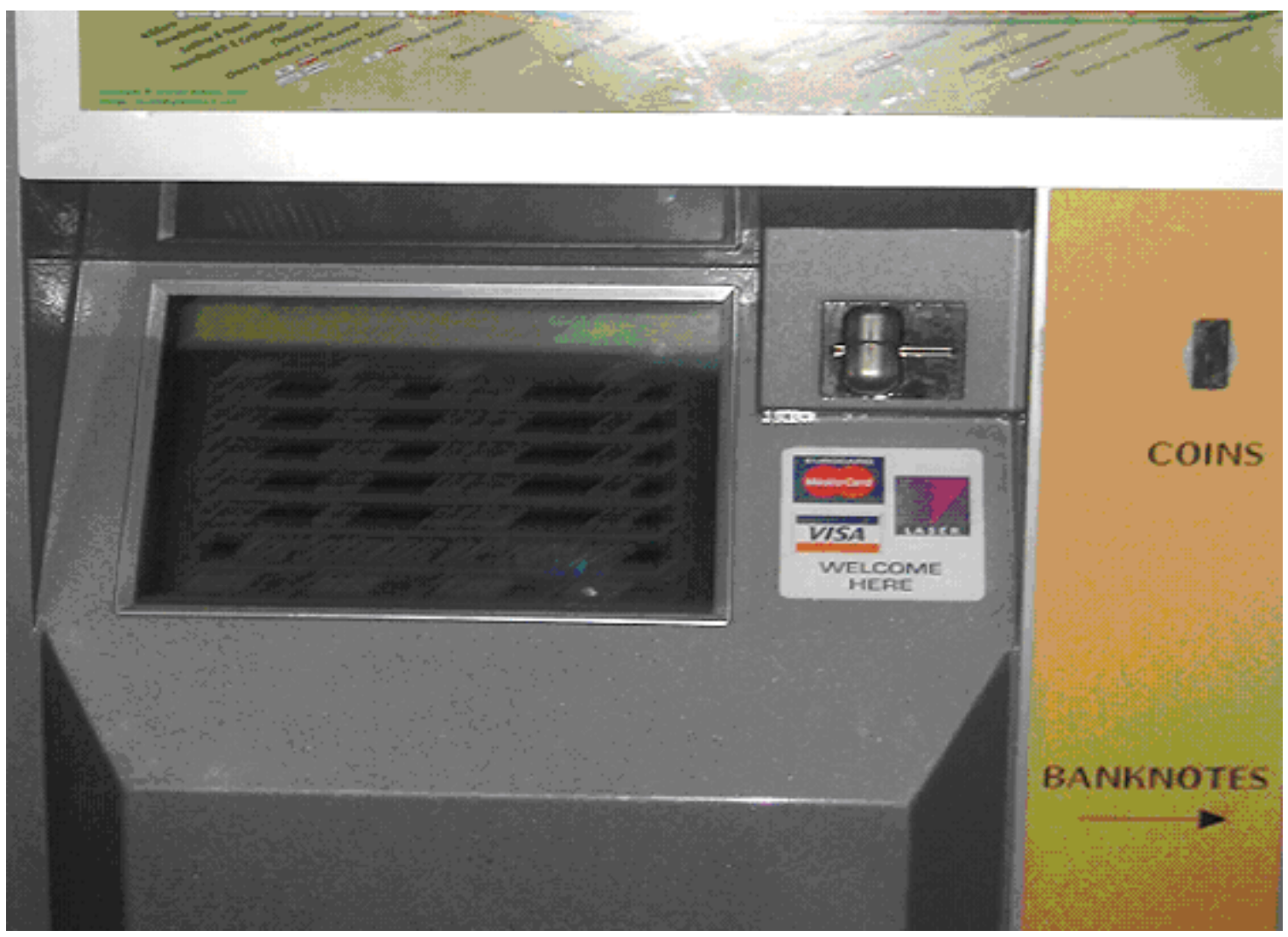

FIGURE 1: IRISH RAIL TICKETING MACHINE 


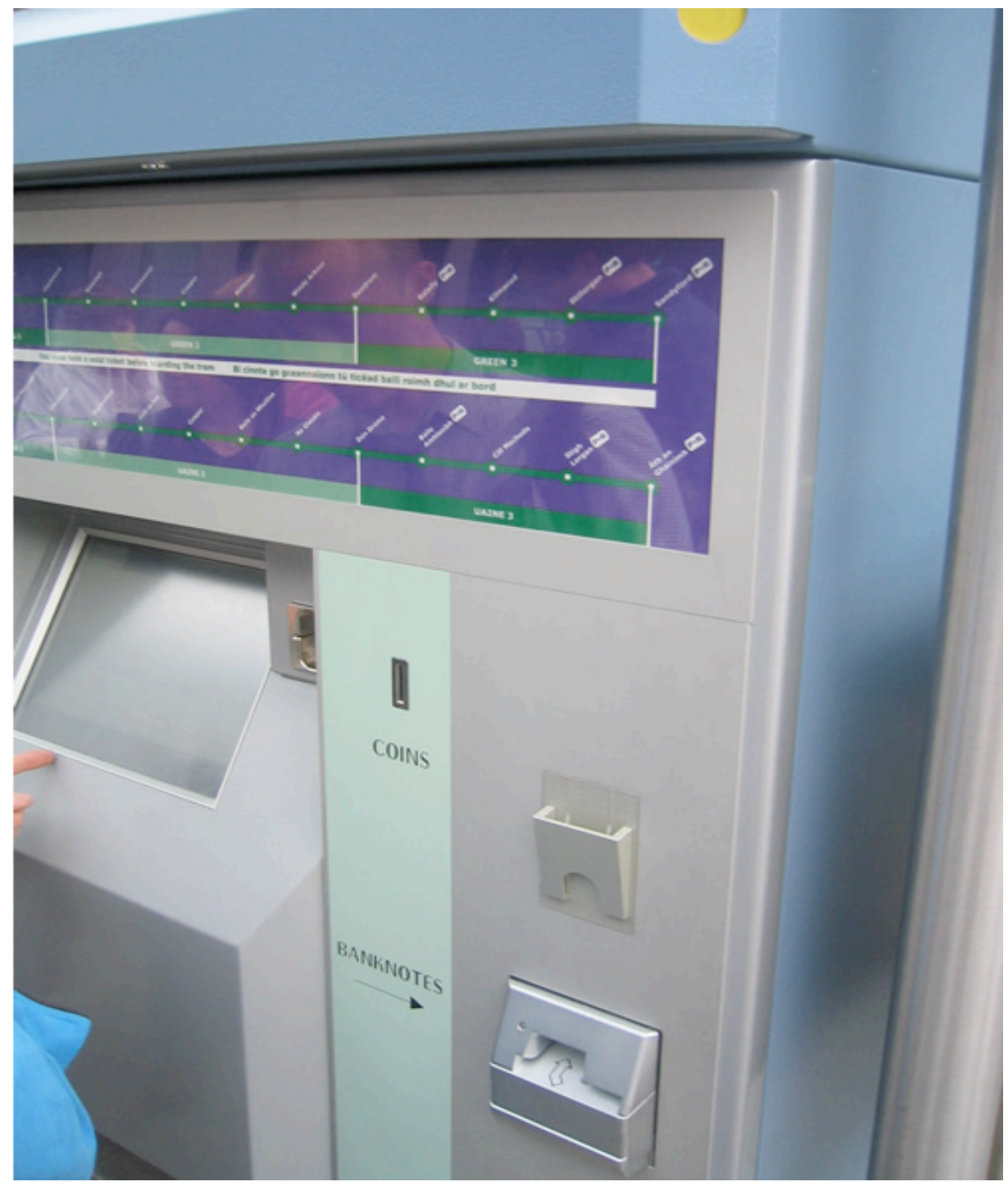

FIGURE 2: LUAS TICKETING MACHINE 


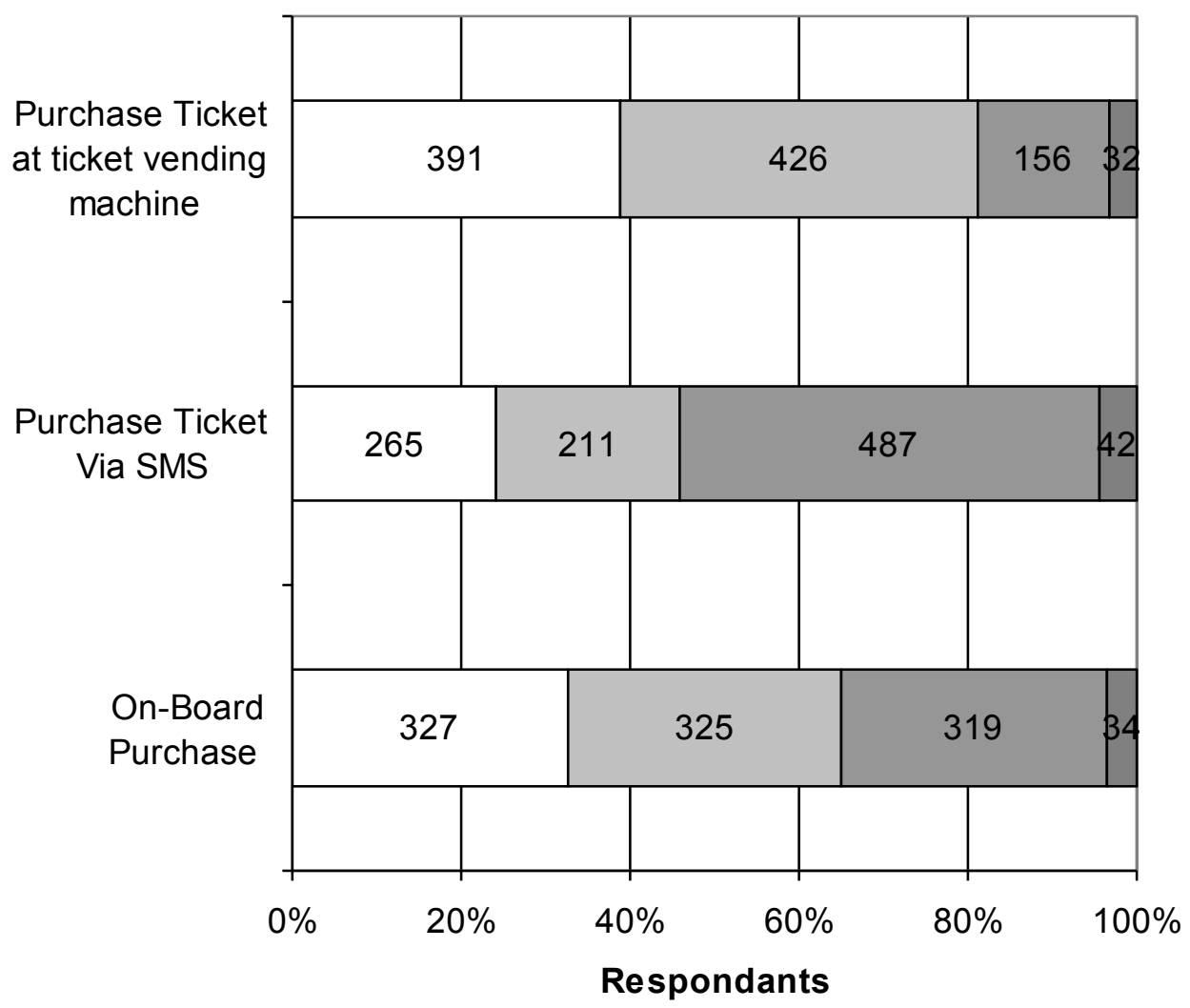

$\square$ First Preference $\square$ Second Preference $\square$ Third Preference $\square$ Don’t Know

FIGURE 3: OPTIONS FOR TICKET PURCHASE 


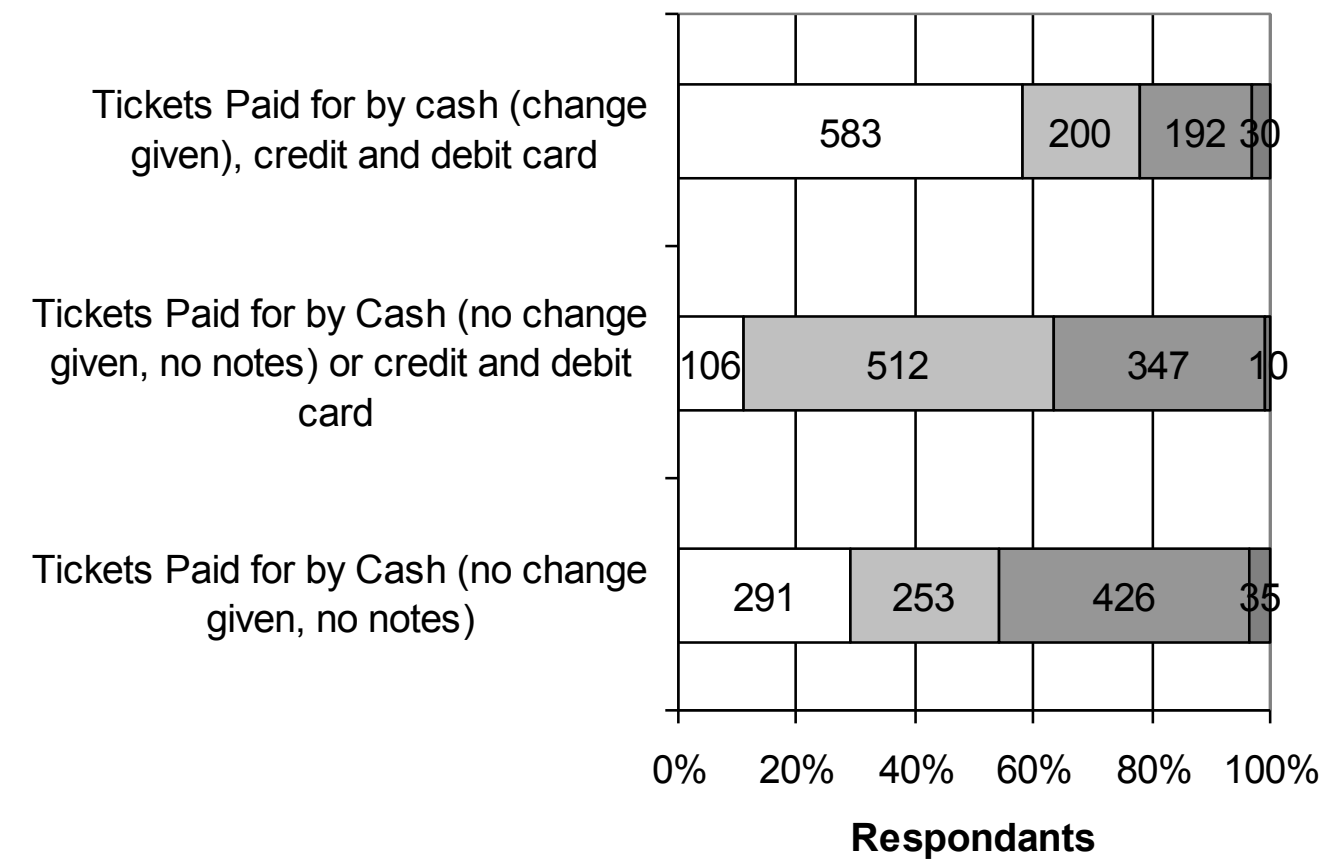

$\square$ First Preference $\square$ Second Preference $\square$ Third Preference $\square$ Don't Know

FIGURE 4: OPTIONS FOR TICKET PAYMENT METHOD 


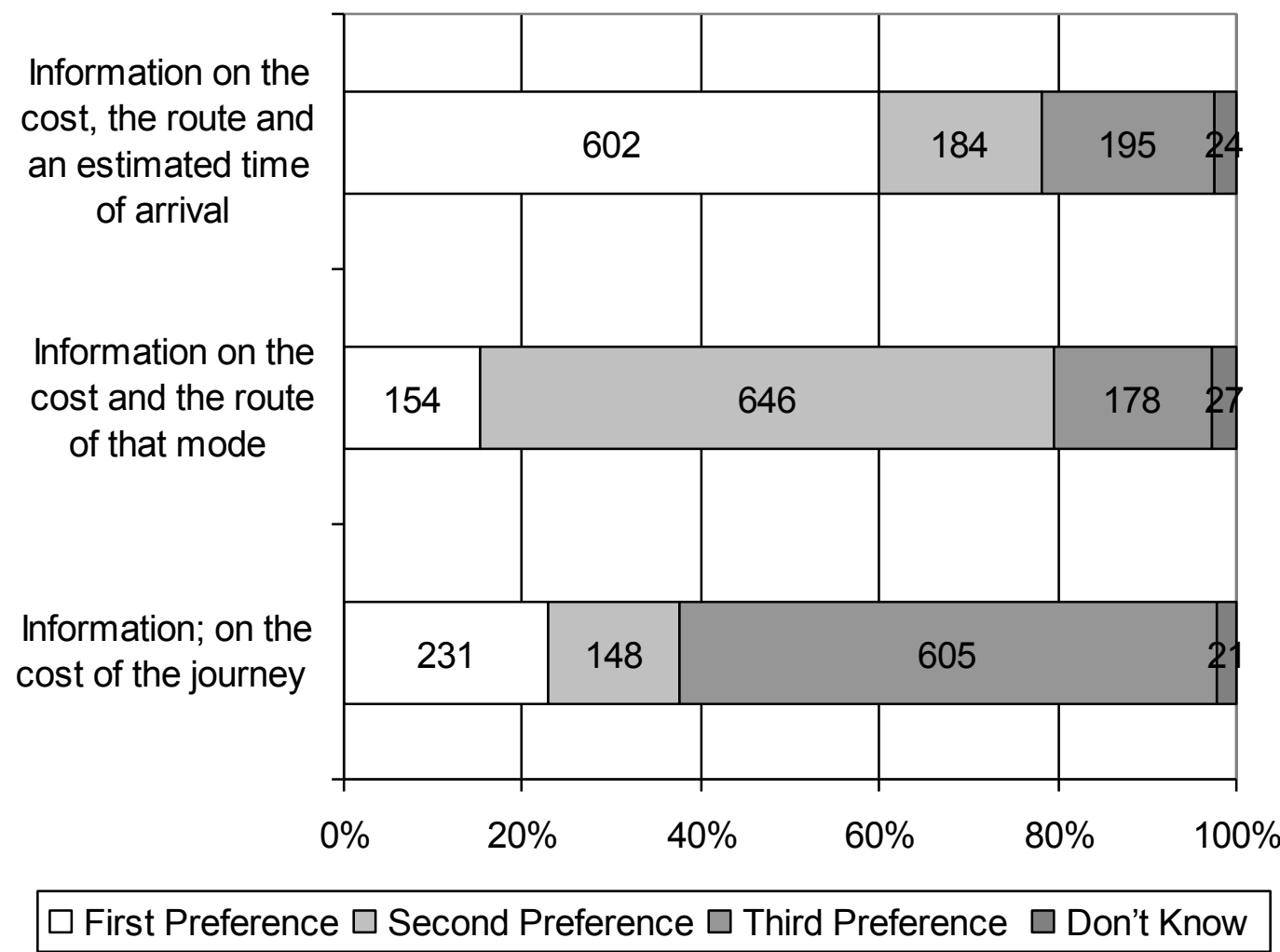

FIGURE 5: INFORMATION PROVIDED 